\title{
Some Language Teaching Methods
}

\author{
Shirinqulova Sitora Muzaffar qizi \\ The Student of Samarkand State Institute of foreign language
}

\begin{abstract}
This article covers ways to learn English, which is one of the most pressing issues to day. In this article, explained new methods of how to learn English language faster and how to learn it.

Key words: the communicative approach, total physical response, the direct method, taskbased language learning, suggestopedia, grammar-translation, the audio-lingual approach

Teaching a foreign language can be a challenging but rewarding job that opens up entirely new paths of communication to students. It's beneficial for teachers to have knowledge of the many different language learning techniques including ESL teaching methods so they can be flexible in their instruction methods, adapting them when needed Keep on reading for all the details you need to know about the most popular foreign language teaching methods. Some of the ones covered are the communicative approach, total physical response, the direct method, task-based language learning, suggestopedia, grammar-translation, the audio-lingual approach and more.
\end{abstract}

\section{Grammar-translation method.}

The grammar-translation method is a method of teaching foreign languages derived from the classical (sometimes called traditional) method of teaching Ancient Greek and Latin. In grammartranslation classes, students learn grammatical rules and then apply those rules by translating sentences between the target language and the native language. Advanced students may be required to translate whole texts word-for-word. The method has two main goals: to enable students to read and translate literature written in the source language, and to further students' general intellectual development. It originated from the practice of teaching Latin; in the early 16th century, students learned Latin for communication, but after the language died out it was studied purely as an academic discipline. When teachers started teaching other foreign languages in the 19th century, they used the same translation-based approach as had been used for teaching Latin. The method has been criticized for its shortcomings.[1]

\section{The Direct Method.}

The direct method of teaching, which is sometimes called the natural method, and is often (but not exclusively) used in teaching foreign languages, refrains from using the learners' native language and uses only the target language. It was established in England around 1900 and contrasts with the grammar-translation method and other traditional approaches, as well as with C.J. Dodson's bilingual method. It was adopted by key international language schools such as Berlitz and Inlingua in the 1970s and many of the language departments of the Foreign Service Institute of the U.S. State Department in 2012.[2]

In general, teaching focuses on the development of oral skills.[3]

Characteristic features of the direct method are:

$\checkmark$ teaching concepts and vocabulary through pantomiming, real-life objects and other visual materials 
teaching grammar by using an inductive approach (i.e. having learners find out rules through the presentation of adequate linguistic forms in the target language)

$\checkmark$ centrality of spoken language (including a native-like pronunciation)

$\checkmark$ focus on question-answer patterns

\section{Audio-lingual method.}

The audio-lingual approach encourages students to develop habits that support language learning. Students learn primarily through pattern drills, particularly dialogues, which the teacher uses to help students practice and memorize the language. These dialogues follow standard configurations of communication.

There are four types of dialogues utilized in this method:

$\checkmark$ Repetition, in which the student repeats the teacher's statement exactly

$\checkmark$ Inflection, where one of the words appears in a different form from the previous sentence (for example, a word may change from the singular to the plural)

$\checkmark$ Replacement, which involves one word being replaced with another while the sentence construction remains the same

$\checkmark$ Restatement, where the learner rephrases the teacher's statement

This technique's name comes from the order it uses to teach language skills. It starts with listening and speaking, followed by reading and writing, meaning that it emphasizes hearing and speaking the language before experiencing its written form. Because of this, teachers use only the target language in the classroom with this TESOL method. Many of the current online language learning apps and programs closely follow the audio-lingual language teaching approach. It is a nice option for language learning remotely and/or alone, even though it's an older ESL teaching method.

\section{Suggestopedia .}

Suggestopedia is a teaching method developed by the Bulgarian psychotherapist Georgi Lozanov. It is used mostly to learn foreign languages.

The theory applied positive suggestion in teaching when it was developed in the 1970s. However, as the method improved, it has focused more on "desuggestive learning" and now is often called "desuggestopedia"[4].

Suggestopedia is a portmanteau of the words "suggestion" and "pedagogy". A common misconception is to link "suggestion" to "hypnosis". However, Lozanov intended it in the sense of offering or proposing, emphasising student choice. Dr. Georgi Lozanov, PhD, MD, presented the method to a commission in Paris at UNESCO, in 1978.[2] UNESCO, then issued a final report in 1980 with positive and negative considerations.[3]

Those negative considerations could never be overcome due to the regime in Bulgaria, which placed Dr. Georgi Lozanov under arrest for 10 years. After his release in 1989, he moved to Austria to continue his studies and teacher training. In 2015, a book about a new method called Neuropedia or Debblocking Method [5] was released, which claims to correct the negative considerations from the final report by UNESCO and adds the newly discoveries of neuroeducation. The author was trained by Dr. Georgi Lozanov, as it is shown on his Trainers Association website, called Litta.

\section{Total Physical Response (TPR).}

The total physical response method highlights aural comprehension by allowing the learner respond 
to basic commands, like "open the door" or "sit down." It combines language and physical movements for a comprehensive learning experience.

In an ordinary TPR class, the teacher would give verbal commands in the target language with a physical movement. The student would respond by following the command with a physical action of their own. It helps students actively connect meaning to the language and passively recognize the language's structure.

Many instructors use TPR alongside other methods of language learning. While TPR can help learners of all ages, it is used most often with young students and beginners. It's a nice option for an English teaching method to use alongside some of the other ones on this list.

An example of a game that could fall under TPR is Simon Says. Or, do the following as a simple review activity. After teaching classroom vocabulary, or prepositions, instruct students to do the following:

$\checkmark$ Pick up your pencil.

$\checkmark$ Stand behind someone.

$\checkmark$ Put your water bottle under your chair.

$\checkmark$ Etc.

\section{Task-Based Language Teaching (TBL).}

With this method, students complete real-world tasks using their target language. This technique encourages fluency by boosting the learner's confidence with each task accomplished and reducing direct mistake correction.

Tasks fall under three categories:

$\checkmark$ Information-gap, or activities that involve the transfer of information from one person, place, or form to another.

$\checkmark$ Reasoning-gap tasks that ask a student to discover new knowledge from a given set of information using inference, reasoning, perception, and deduction.

$\checkmark$ Opinion-gap activities, in which students react to a particular situation by expressing their feelings or opinions.

Popular classroom tasks practiced in task-based learning include presentations on an assigned topic and conducting interviews with peers or adults in the target language. Or, having students work together to make a poster and then do a short presentation about a current event. These are just a couple of examples and there are literally thousands of things you can do in the classroom.

It's considered to be a modern method of teaching English. I personally try to do at least 1-2 taskbased projects in all my classes each semester. It's a nice change of pace from my usually very communicative-focused activities.

One huge advantage of TBL is that students have some degree of freedom to learn the language they want to learn. Also, they can learn some self-reflection and teamwork skills as well.

\section{HERE ARE SOME WAYS THAT DEBATING CAN BENEFIT YOU:}

$>$ Improved Critical Thinking Skills...

$>$ Improved Research Skills...

$>$ Improved Articulation... 
Quick-thinking...

$>$ Resolution of Conflict...

$>$ Greater Empathy...

$>$ Emotional Control...

$>$ Finding Meaning in Complex situations...

If these methods are used in many educational Institutions, students will have more opportunities to learn the language, which help them in the future.

\section{References:}

1. Zhou, G. \& Niu, X. (2015). Approaches to language teaching and learning. Journal of Language Teaching and Research, 6(4), p. 798

2. http://inlingua.com

3. http://www.inlinguabeograd.com/learn_serbian.php?lang=en\&web_page_ls=About\%20school

4. Lozanov, Georgi. Suggestology and Suggestopedy http://lozanov.hit.bg/4/30/2006

5. Negrete, Paulo Sergio (2015). Suggestopedia/Neuropedia - Theory and Practical Application in TEFL Courses. Brazil. pp. 20-25. 